\title{
PRACTICAL STABILITY OF DIFFERENTIAL EQUATIONS WITH NON-INSTANTANEOUS IMPULSES
}

\author{
Ravi Agarwal, Snezhana Hristova and Donal O’REgan
}

\begin{abstract}
The concept of practical stability is generalized to nonlinear differential equations with non-instantaneous impulses. These type of impulses start their action abruptly at some points and then continue on given finite intervals. The practical stability and strict practical stability is studied using Lyapunov like functions and comparison results for scalar differential equations with non-instantaneous impulses. Several sufficient conditions for various types of practical stability, practical quasi stability and strict practical stability are established. Some examples are included to illustrate our theoretical results.
\end{abstract}

Mathematics subject classification (2010): 34A34, 34A08, 34D20.

Keywords and phrases: Non-instantaneous impulses, practical stability, Lyapunov like functions.

\section{REFERENCES}

[1] R. P. Agarwal, S. Hristova, Strict stability in terms of two measures for impulsive differential equations with 'supremum', Appl. Anal. 91, 7, (2012), 1379-1392.

[2] R. Agarwal, S. Hristova, D. O'Regan, Lyapunov functions and strict stability of Caputo fractional differential equations, Adv. Diff. Equ. 015, 91, (2015), 346, doi:10.1186/s13662-015-0674-5.

[3] Ravi Agarwal, D. O'Regan, S. Hristova, Stability by Lyapunov like functions of nonlinear differential equations with non-instantaneous impulses, J. Appl. Math. Comput. (2015), doi10.1007/s12190-015-0961-z.

[4] S. R. Bernfeld, V. Lakshmikantham, Practical stability and Lyapunov functions, Tohoku Math. J. 32, (1980), 607-613.

[5] M. FeCKAN, J. R. WANG, Y. ZHou, Periodic solutions for nonlinear evolution equations with noninstantaneous impulses, Nonauton. Dyn. Syst. 1, (2014), 93-101.

[6] E. Hernandez, D. O'Regan, On a new class of abstract impulsive differential equations, Proc. Amer. Math. Soc. 141, (2013), 1641-1649.

[7] S. G. HRistova, Practical stability and cone valued Lyapunov functions for differential equations with "maxima", Int. J. Pure Appl. Math. 57, 3, (2009), 313-323.

[8] S. HRistova, Generalization of practical stability for delay differential equations with respect to initial time difference, AIP Conf. Proc. 1570, 313 (2013).

[9] S. Hristova, Qualitative investigations and approximate methods for impulsive equations, Nova Sci. Publ. Inc., New York, 2009.

[10] S. Hristova, A Georgieva, Practical stability in terms of two measures for impulsive differential equations with “supremum”, Int. J. Diff. Equ. 2011, (2011), Article ID 703189, 13 pages.

[11] S. G. Hristova, K. STEFAnOva, Practical stability of impulsive differential equations with "supremum” by integral inequalities, Eur. J. Pure Appl. Math. 5, 1, (2012), 30-44.

[12] V. Lakshmikantham, D. D. Bainov, P. S. Simeonov, Theory of Impulsive Differential Equations, World Scientific, Singapore, 1989.

[13] V. Lakshmikantham, S. Leela, Differential and Integral Inequalities, vol. I, Academic Press, New York, 1969.

[14] V. Lakshmikantham, S. Leela, A. A. Martynyuk, Practical Stability of Nonlinear Systems, World Scientific, Singapore, 1990. 
[15] V. Lakshmikantham, Y. Zhang, Strict practical stability of delay differential equation, Appl. Math. Comput. 118, 2-3, (2001) 275-285.

[16] A. A. Martynyuk, Practical stability of motion, Naukova Dumka, Kiev, 1983, (in Russian).

[17] D. N. PANDEy, S. DAS, N. SukaVAnam, Existence of solutions for a second order neutral differential equation with state dependent delay and not instantaneous impulses, Intern. J. Nonlinear Sci. 18, 2, (2014), 145-155.

[18] M. PierRi, D. O'Regan, V. Rolnik, Existence of solutions for semi-linear abstract differential equations with not instantaneous impulses, Appl. Math. Comput. 219, (2013), 6743-6749.

[19] A. Sood, S. K. SRIVAstava, On stability of differential systems with noninstantaneous impulses, Math. Probl. Eng. 2015, (2015), Article ID 691687, 5 pages.

[20] J. WANG, Z. LIN, A class of impulsive nonautonomous differential equations and Ulam-HyersRassias stability, Math. Meth. Appl. Sci. 38, 5, (2015), 868-880. 